\title{
BILINGUAL BEHAVIOUR CHECKLISTS: INITIATING A STUDENT, TEACHER AND PARENT PARTNERSHIP IN BEHAVIOUR MANAGEMENT
}

\section{TED GLYNN}

Department of Professional Studies

University of Waikato

\section{MERE BERRYMAN \\ WAI HARAWIRA \\ KATHRYN ATVARS \\ PAULINE BIDOIS}

Poutama Pounamu Education Research Centre

Specialist Education Services

ABSTRACT Three bilingual (Māori and English) behavioural checklists formed part of a project designed to facilitate student, teacher and whanau collaboration in overcoming behavioural difficulties experienced by Mãori students, (Hei Awhina Matua). The checklists assessed rankings by 163 students, 21 teachers and 96 whanau members of (1) contexts in which problem behaviours occur, (2) specific problem behaviours and (3) specific most valued behaviours. Data were gathered in three schools: a mainstream intermediate school with a Māori medium syndicate of three classes, a rural Kura Kaupapa Māori (Māori-controlled total immersion school) and a bilingual contributing primary school. While the three schools differed markedly in location, size, and in the proportion of Mäori students enrolled, the rankings of settings and behaviours by students, teachers and whanau in each school were highly similar. The paper discusses how these data contributed to the design and development of the Hei Awhina Matua video and training manual, and provided a first step towards a collaborative student teacher and parent partnership in the management of student behaviour.

Parents and teachers are being increasingly challenged by the behavioural and learning difficulties their students experience at home and at school (Glynn, Fairweather \& Donald, 1992). The rate of truancies, suspensions and expulsions from New Zealand schools continues to grow alarmingly (Jacka, Sutherland, Peters \& Smith, 1996). Of special concern is the disproportionate number of Māori children and their families who are experiencing the negative impact of behavioural difficulties. The difficulties experienced by Māori families are exacerbated when schools respond to their children's behaviour in ways that ignore cultural concerns and the contexts in which student behaviour occurs (Glynn, Harawira, Stockman, Gear, Walker, Reweti, Berryman, Atvars \& Bidois, 1996). This is even more problematic when 
teachers belong to a different ethnic group from that of their students or when schools utilise behavioural programmes that have been developed in other countries and with other cultural groups.

Sociocultural perspectives on human learning emphasise the importance of the responsive social and cultural contexts in which learning takes place (McNaughton, 1994; Valsiner, 1987; Vygotsky, 1987; Youniss, 1994). They stress the importance of positive social relationships between children and parents or teachers for effective learning to occur. Intellectual learning and social learning are seen as interdependent. The Hei Awhina Matua home and school behaviour management programme attempts to work within such a perspective (Glynn, Berryman \& Atvars, 1996). Hei Awhina Matua encourages students, teachers and whanau members to work together to develop solutions which are more culturally acceptable. This approach tries to avoid having teachers attribute students' behavioural difficulties to perceived inadequacies of parents, and having parents attribute those same difficulties to perceived inadequacies of teachers. Rather, a collaborative partnership between teachers, parents and students is sought through the sharing of detailed information as well as human resources and skills. Students are the common group who form the link between teachers and whanau (family) members, and for whom teachers and whanau members are jointly responsible.

Hei Awhina Matua acknowledges the issue of tino rangatiratanga by adopting a kaupapa Māori (collective vision or philosophy) approach to educational research and development. In this approach, kaumatua and kuia (elders) exercise their important leadership role. They ensure that Māori language, cultural values and preferred practices are kept to the fore. They see that appropriate kawa (Māori customs) are followed at all meetings between students, teachers and parents. They provide a safeguard that behaviour change procedures and strategies developed and implemented are compatible with tikanga (customs and practices) appropriate to their iwi (tribe). The researchers, working under the guidance of kaumatua and kuia strove to operate as a research whanau or whanau-of-interest (Bishop, 1994; Bishop, 1996a, 1996b; Glynn \& Bishop, 1995) so that control over the research questions, methodology, data and interpretation remain with Māori. Being members of this whanau facilitated the authors' listening to the educational aspirations and concerns being raised by Māori parents as well as by Māori students (Glynn, Berryman, Bidois, Atvars, Duffull \& Horne 1996). Being a member of a whanau of interest also enabled the first author, a tauiwi (non-indigenous) researcher, to contribute research and behaviour change strategies in culturally appropriate ways, (Glynn, Harawira, Stockman, Gear, Walker, Reweti, Berryman, Atvars \& Bidois, 1996).

Prior to selecting behaviour change strategies for inclusion among resource materials in an intervention programme such as Hei Awhina Matua, it was crucial to obtain data on problem settings and behaviours which were of greatest concern for Māori students and their teachers and whanau. Researchers began by collaborating with the three teachers of Māori medium classes in School 1 to produce two checklists designed to establish the school, home and community settings in which problem behaviours occurred, and to identify specific problem behaviours themselves. 
These checklists were entitled: Working through the Day at Home and School (Problem Context Checklist) - Tables 1 and 4, Behaviour that Bothers Us at Home or at School (Problem Behaviour Checklist), - Tables 2 and 5. Since the checklists were part of a programme intended to contribute to positive behaviour change, it was important not to focus exclusively on negative behaviour. Hence, there was a need to identify and record desired positive or valued behaviours, and so a third checklist, Behaviours We Like to See at Home or School (Most Valued Behaviour Checklist) was also developed (Tables 3 and 6). The checklists were designed to answer three questions from the perspective of students, school staff and whanau members:

(1) What are the specific contexts and settings in which students experience behavioural and learning difficulties at home and at school?

(2) What are the specific behavioural difficulties encountered by students at home and at school?

(3) How are these contexts and behaviours prioritised?

\section{METHOD}

\section{Procedure}

School 1 was a large urban intermediate, with over 300 students, of whom $30 \%$ were Māori. The school comprised a Māori medium syndicate and two mainstream syndicates. The Māori medium syndicate consisted of three classes, each with its own unique characteristics.

The first class had 20 students and was working towards $80 \%$ immersion in te reo Māori (Māori language). This class was taught by a female teacher who was a fluent Māori speaker. Students needed to have a high level of te reo to enter this class. Most came from an immersion class or kura kaupapa background, but a few came from the intermediate's bilingual class. The immersion class was supported by a kaiarahi i te reo (a Māori language assistant) who was a kuia (woman elder) and a fluent native speaker.

The second class was bilingual and had 30 students. Entry into this class was via previous experience in Māori medium education. The bilingual class was working towards $50 \%$ Māori immersion.

The third class was an enrichment class of 33 students who had no background in Māori medium education. However, these students were highly motivated to learn Māori and strove hard to be selected into this class. The teacher was still developing her own competence in te reo Māori

At the time of the study, the bilingual class had been established for five years, while the immersion and enrichment classes were newly established. Seventy-five of the 83 students in the three classes in the Māori medium syndicate were Māori. The syndicate was supported by a male kaiawhina (teacher aide) who provided support with the boys' welfare and was also responsible for tikanga related to the male disciplines, e.g. haka (former war dance now an essential component of cultural performances), wero (formal challenge used during rituals of encounter), taiaha (a traditional martial art involving a hand-held staff) and whaikorero (oratory). 
The checklists were trialled with students in School 1, and their input was sought to verify the "street credibility" of the language and item content. The researchers were surprised and delighted at the seriousness and the depth of the students' response to this invitation. Students affirmed and extended the colloquial language used in the checklists and the settings identified by the teachers and researchers. This began a continuing process of student consultation and involvement which saw them exerting increasing control over the Hei Awhina Matua research and resource development. Several of these students assisted in presenting preliminary data to a Ministry of Education Research Advisory Committee. As a result of this, two of the students were funded by the Ministry to present a paper with the authors on children's involvement in research at a national conference, Investing in Children, at the Children's Issues Centre, Dunedin, (Glynn, Berryman, et al., 1996).

A hui (community meeting) between students, whanau members, staff of the Māori medium syndicate and the researchers was called to introduce the Hei Awhina Matua programme, and to invite all participants to complete the three checklists. Strong incentive for whanau members to attend was provided by inviting parents and whanau to view their children performing in the school's kapahaka (cultural) group. Kuia and kaumatua participated and karakia (prayer) and mihi (greetings and introductions) were an essential part of the proceedings. Students and whanau members independently completed the checklists at this meeting. School staff were also invited to complete the checklists later in the week. Each of the checklist items allowed responders to rate how frequently specific behaviours and contexts were of concern to them. They rated each item on a four-point scale ( 0 , never; 1 , sometimes; 2 , often; 3 , aiways) (refer Tables 1, 2 and 3).

Following the community meeting, responses to the checklists were collated separately for students, school staff and whanau members. From the individual responses to every item, a mean score for each responder group (students, school staff and whanau members) for every item was computed. Item mean scores were then ranked from highest to lowest, for each responder group.

The 10 highest-ranked items from each of the three checklists provided a framework for constructing the Hei Awhina Matua video and training manual. This video incorporated 11 skits which deal with behaviours and settings ranked most problematic by students, school staff and whanau members in School 1. The training manual provides workshop material to assist students, school staff and whanau members to suggest ways of improving on the behavioural interactions depicted in the video.

School 2 was a small rural kura kaupapa Māori School with approximately 100 students. This school had just recently acquired kura kaupapa Māori status and was the first school of its kind in the area. The school had a non-teaching principal and four classroom teachers supported by a kaiarahi $i$ te reo and a kaiawhina. A caretaker and a clerical assistant made up the rest of the staff. Two tertiary students from Te Rangakura (a Māori teacher education programme) were also working in the school at the time of the study. 
Almost all of students at School 2 were bussed in from two separate urban areas. One of the buses was shared with a nearby college, an intermediate school (School 1), and a mainstream primary school. The few remaining students at School 2 travelled by car, except for students from one family who lived close enough to walk. Trialling the checklists in School 2 required presenting them in the Māori language. The Māori versions of the three checklists were entitled Ngā wa me Ngā wahi $i$ Te Kainga $i$ Te Kura Ranei, (Table 4), Nga Whanonga Whakararuraru $i$ a Tatou $i$ Te kainga, $i$ Te Kura Ranei, (Table 5), and Nga Whanonga Pai ki a Matou i Te Kainga i Te Kura Ranei (Table 6). This was not simply a matter of straightforward translation. The third author, a fluent native speaker from the Tuhoe tribe, and Specialist Education Services Kaiwhakahaere (National Office Māori Management Team), undertook the challenging task of expressing the wide range of behavioural concepts in traditional Māori style. For example, "withdrawal" became te whakamotu i a koe ano (to make an island of yourself), "tagging" became tuhi whakaparuparu (writing which makes things dirty).

As was the case with School 1, a hui was called so that whanau and school staff could fill out the checklists at school. This task followed whanau members watching their children's kapahaka performance. The hui began with a powhiri (formal ritual of encounter) to welcome the research whanau and some new families into the school. After the powhiri the students performed. These performances demonstrated the positive achievement of students and staff alike as well as the pride and support of the community. Both Māori and English versions of the checklists were then provided for the whanau members to fill out. Year 6 to 8 students had responded to the checklists earlier in the week. Checklists had been administered in Māori by one of the teachers. All students and school staff completed the Māori versions, while the majority of whanau members chose to complete the English versions.

Mean scores for each of the three responder groups were ranked for every checklist item, following the same procedure as described for School 1.

School 3 was a small bilingual contributing school situated in a semi-rural location. There were three classrooms. The Year 1 to 3 students were in a Rumaki (Māori immersion) programme as was the Standard 1 to Standard 2 classroom. At Year 5 and 6 the students moved into a transition programme where immersion in English was introduced for one day of the week. At the end of Year 6, students from this school moved on to the intermediate identified in this paper as School 1. The total roll number in this school was 64 . School 3 has well established grounds which include a full size rugby field, netball court, adventure playground and swimming pool complex.

School 3 was staffed by a teaching principal, a 0.3 Scale A position which provided principal release time and two full-time scale A teachers. The board of trustees employed a full-time Kaiarahi Reo and part-time Kaiawhina as support staff to help reflect the special nature of the school. A part time teacher aide, clerical assistant and caretaker/cleaner made up the rest of the permanent staff. Three tertiary students from Te Rangakura were also working in the school at the time of the study. 
The majority of students at this school travelled to school as pedestrians or cyclists. A few travelled to school by car and none travelled by bus. However, buses were sometimes used for travel when class or school trips took place.

Unlike Schools 1 and 2 where the checklists were trialled with Year 7 and 8 students, the checklists in School 3 were trialled with the students. Because of the bilingual nature of the classroom, the Māori versions of the checklists were presented to all but four of the students with instructions and clarifications given in English. Four recently-enrolled students who had come from mainstream English programmes were given the English version of the checklist to fill out. The checklists in School 3 were administered by the researcher and the classroom teacher on two occasions. Interested whanau members had been invited along to observe the students responding to the checklists and on each occasion there were some whanau members present.

Parents and whanau members were invited by the board of trustees to an early evening meeting held at the school, to find out about the Hei Awhina Matua project and fill out the checklists. Children in School 3 did not participate in kapahaka performance at this meeting although a small number were present playing in the school grounds. A group including the principal, kaumatua, whanau, and school trustees attended. Kaupapa Māori procedures were followed and the checklists were completed. Some whanau members took checklists home for other members to fill out. These were returned, completed, to the researchers the next day. School staff members were given a week to complete the checklists.

Mean scores for each of the three responder groups were ranked for every checklist item, following the same procedure as described for Schools 1 and 2.

Mean ranks across all three school were calculated item by item, to provide an overall mean rank for each responder group. The 10 items with overall mean ranks above 0.9 on the 0 to 3 scale are listed for each responder group (Tables 2, 3 and 4). A double tick indicates that responder groups in each school had ranked an item in their top 10. A single tick indicates that responder groups in each school had ranked an item between 11 and 15 . No tick indicates that an item was not ranked in the top 15.

\section{RESULTS}

Common problem contexts identified among students, whanau members and school staff are shown in Figure 1. Table 7 lists the 10 highest ranked items on the Problem Context Checklist by school and by responder group. Data analysis showed that students' mean ranks ranged from 1.07 to $1.24,(x=1.02)$. The corresponding whanau members' mean ranks ranged from 0.97 to $1.63,(x=$ 1.19). The corresponding school staff mean ranks ranged from 1.19 to $1.58,(x=$ 1.30). There was minimal difference of the ranking of the overall problem contexts among any of the responder groups. 


\section{Problem Contexts}

\section{All responders from School One, School Two and School Three}

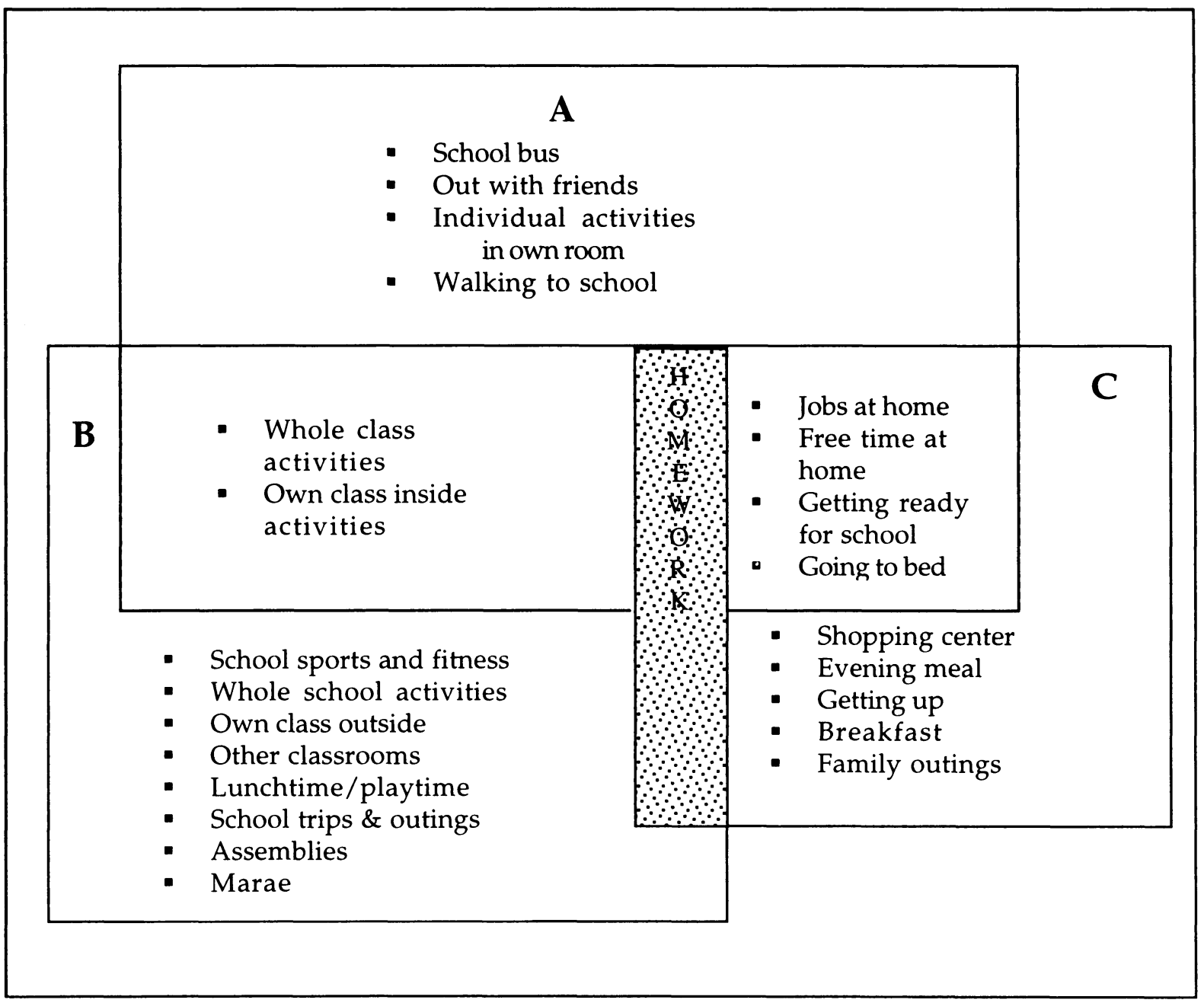

Key for Responder Groups
$\mathrm{A}=$ Students
$B=$ School staff
$C=$ Whanau Members

Figure 1: Intersection of highest ranking problem contexts identified by students, teachers and whanau members from School 1, School 2 and School 3. 
Common problem behaviours identified among students, whanau members and school staff are shown in Figure 2. Table 8 lists the 10 highest ranked items on the Problem Behaviour Checklist. Students' mean ranks ranged from 1.12 to $1.71,(x=1.30)$. The corresponding whanau members' mean ranks ranged from 0.97 to $1.84,(x=1.31)$. The corresponding school staff mean ranks ranged from 1.08 to $1.64,(x=1.28)$. There was minimal difference in the overall ranking of problem behaviours among any of the respondent groups.

Common behaviours identified as most valued among students, whanau members and school staff are shown in Figure 3. Table 9 lists the 10 highest ranked items on the Most Valued Behaviours Checklist. Students' mean ranks ranged from 1.54 to $1.91,(x=1.64)$. The corresponding whanau members' mean ranks ranged from 1.90 to $2.12,(x=2.01)$. The corresponding school staff members' mean ranks ranged from 1.80 to $2.13,(x=1.88)$.

Students, whanau members and school staff in all three schools gave their highest rankings to items from the Most Valued Behaviours Checklist. Overall, whanau members ranked these behaviours more highly than staff members or students themselves. In School 1, whanau members ranked 21 of the 26 most valued behaviours higher than students or school staff. In school 3 , whanau members ranked 24 of the 26 items higher than school staff, and 20 items higher than students. However, in School 2, school staff members ranked 24 of the 26 most valued behaviours higher than students or whanau members. Students from all three schools ranked "playing together" very highly. (This item was ranked first by students in School 1, third equal by students in School 2 and second by students in School 3.)

Data in Table 7 (Problem Context Rankings) indicate that students and staff from all three schools identified travelling to school, whether by bus (School 1 and 2) or on foot (School 3), among their top 10 individual contexts for problem behaviour. As noted earlier, a high proportion of students from School 2 and from the Māori medium syndicate in School 1, travelled to school by bus, some of them, on the same bus. This bus, while legally loaded, was nevertheless overcrowded.

Whanau members' rankings (Table 7) indicated they were concerned mainly with those contexts in which they themselves had direct responsibility for their children. Home behaviour contexts where whanau members wanted their children to do things were the more problematic. Doing jobs at home was ranked highest by whanau members and this was closely followed by contexts calling for independent personal care skills, which form part of daily routines. Students too were more concerned about contexts involving their doing jobs at home. However Figure 2 indicates that they ranked good personal care skill as a most valued behaviour. Both parents and students were concerned about free time as a problem context at home (Table 7).

Students from School 1 and School 2 ranked "going out with friends" among their problem behaviour contexts, (fourth equal in School 1, and seventh in School 2). The younger students from School 3 did not rank "going out with friends" among their top 15 problem behaviour contexts. The overall student mean ranking of "going out with friends" was ninth. Whanau members however, did not rank this context among their top 10. 


\section{Problem Behaviours}

All responders from School One, School Two and School Three

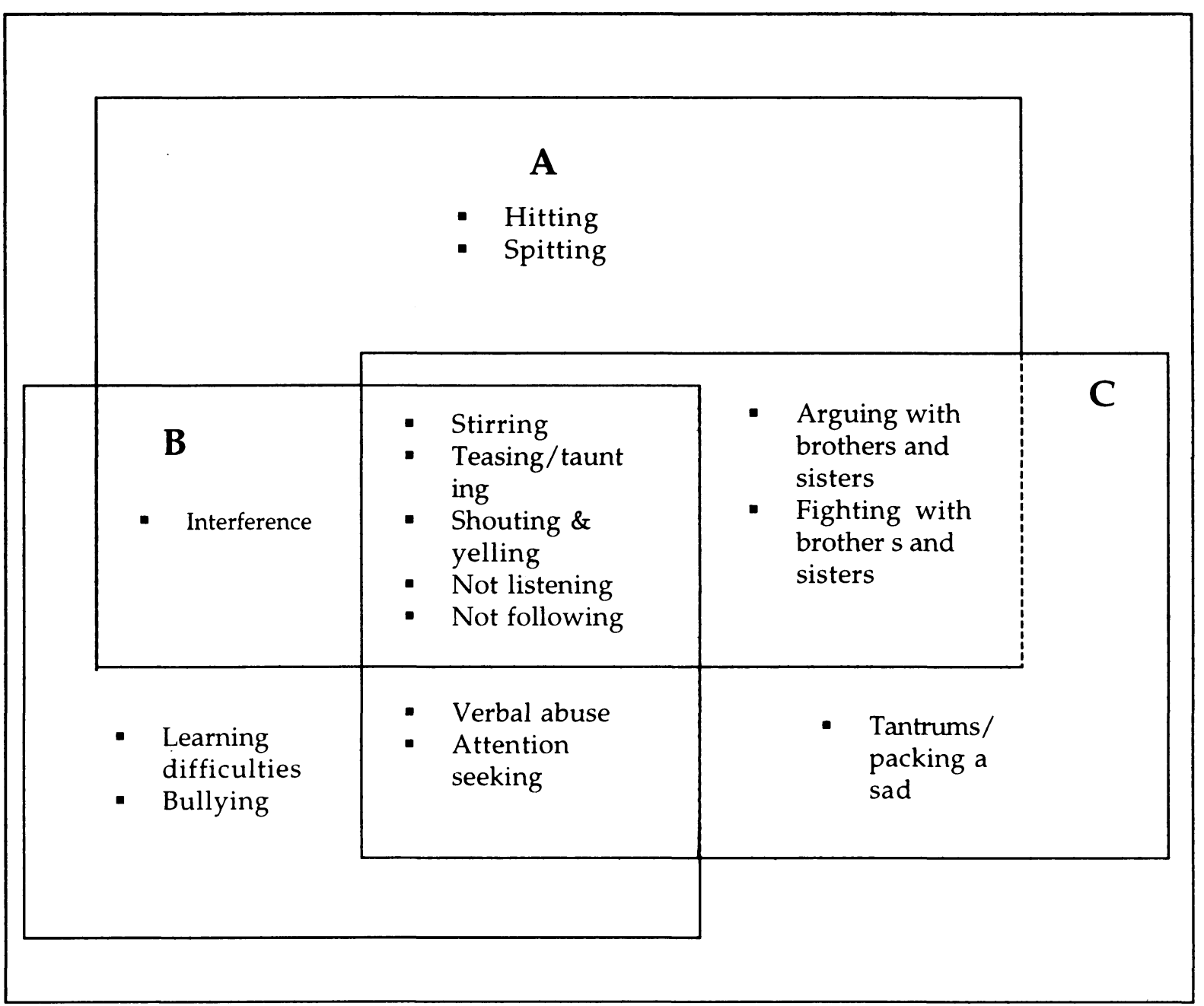

\section{Key for Responder Groups}
$\mathrm{A}=$ Students
$B=$ School staff
$\mathrm{C}=$ Whanau Members

Figure 2: Intersection of highest ranking problem behaviours identified by students, teachers and whanau members from School 1, School 2 and School 3. 
School staff and whanau members ranked highly problem contexts that were of concern to themselves alone. School staff ranked lunchtime, playtime, school trips, outings, assemblies, whole school activities and other classrooms as problem contexts. Whanau members ranked getting up, breakfast and family outings as problem contexts. Students ranked some items in common with whanau or school staff groups. Whole class activities and own classroom inside activities were ranked highly by students and school staff, while jobs at home, free time at home, getting ready for school and going to bed were ranked highly by students and whanau members. This relationship is clearly seen in Figure 1 which shows the common contexts of concern for all three responder groups.

Homework was the only item to be identified in the top priority list by all responder groups. Students and whanau members rated it sixth, and school staff rated it 10 th.

Table 8 shows rankings of items from the problem behaviours checklist. Students and whanau from all three schools clearly indicated that their two most problematic behaviours involved sibling interaction, (fighting with brothers and sisters and arguing with brothers and sisters). Additional items ranked highly by whanau members also appeared to be related to sibling interaction, namely: not listening, shouting and yelling, not following instructions, teasing, taunting, and stirring. These items were also ranked highly by students and school staff, but in a slightly different order. Further whanau members and school staff ranked verbal abuse and attention seeking among their 10 priority rankings.

Bullying, which had an overall mean ranking of $10^{\text {th }}$ by school staff, did not appear among either the student or whanau member priority rankings. Figure 3 shows that problem behaviours that were ranked highly by the whanau members and students were also ranked highly by school staff (e.g. stirring, teasing, taunting, shouting, yelling, not listening and not following instructions).

\section{DISCUSSION}

The three behaviour checklists available in either Māori or English appeared to be user friendly for student, teacher and whanau groups in all three schools. Teachers from School 2, the kura kaupapa, commented positively on the appropriateness of the Māori used by the third author in the Māori language versions. No confusion or difficulty in understanding any item was reported for either the English version filled out in School 1 or the Māori language version filled out in School 2. In School 3 the bilingual students had access to both the English and Māori versions. The description of contexts and behaviours within the checklists appeared familiar and appropriate to all responder groups. The checklists served to encourage responders to think about a wide range of different contexts and behaviours, rather than focus entirely on issues of concern to a few individuals. 
Most Valued Behaviours

All responders from School One, School Two and School Three

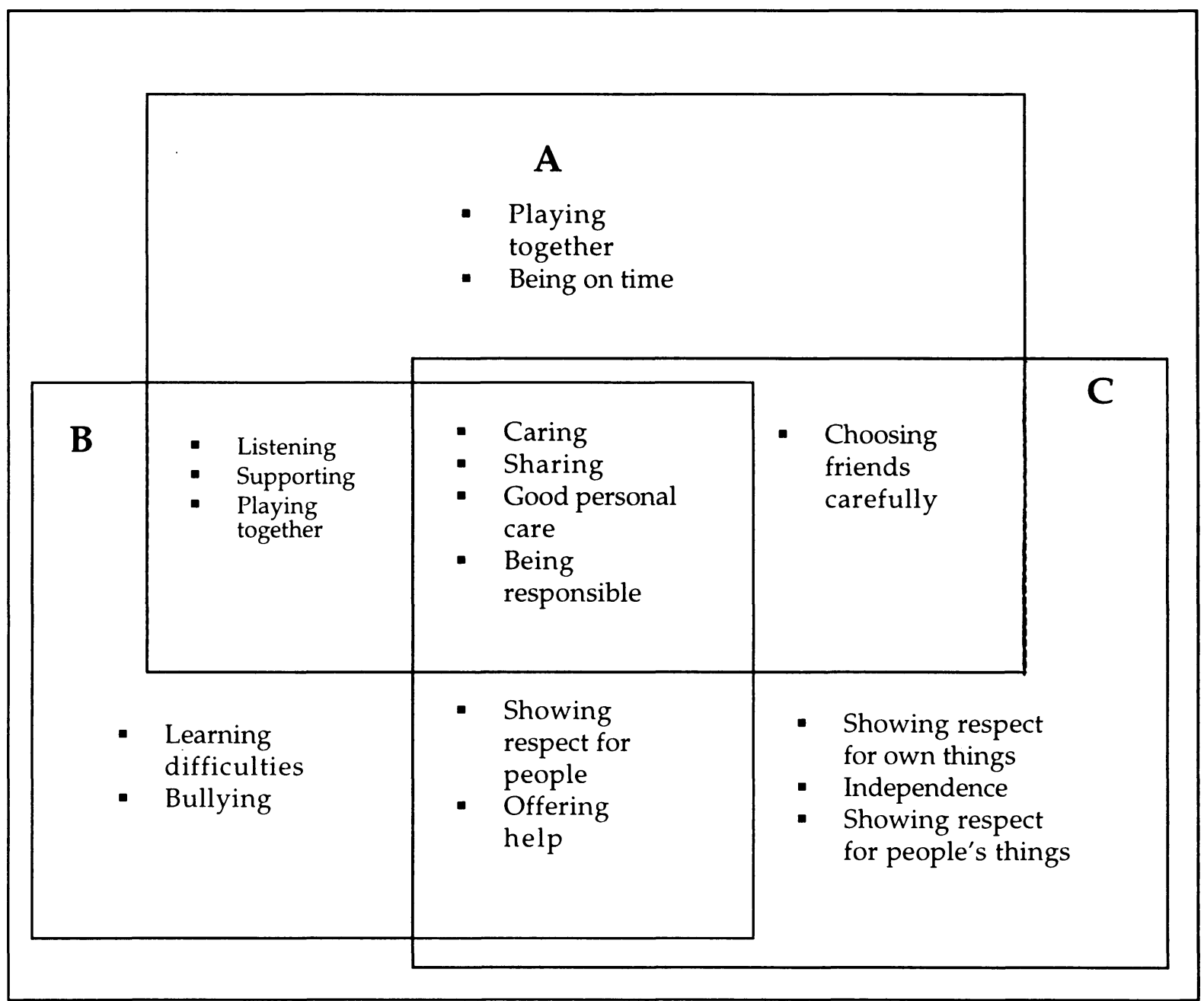

Key for Responder Groups
$\mathrm{A}=$ Students
$B=$ School staff
$\mathrm{C}=$ Whanau Members

Figure 3: Intersection of highest ranking most valued behaviours identified by students, teachers and whanau members from School 1, School 2 and School 3. 
Presentation of the checklists took place within teacher and whanau hui, which in School 1 and School 2 included kapa haka performances by students. This enabled data to be gathered in a relaxed, non-threatening, enjoyable and culturally-safe setting. In School 3, the board of trustees undertook the communication with parents and organisation of the whanau hui, but a kapahaka performance was not included on the agenda. Fewer staff, whanau members and students attended. However, cultural safety was ensured in all three schools through the following of kaupapa Māori procedures during all visits to the school and with whanau members. Students, whanau members and teachers completed the checklists willingly in the knowledge that they were helping to provide a database which would serve to guide the construction of the Hei Awhina Matua video, training manual and resources aimed at improving behaviour in home, school and community settings. This supportive context needs to be taken into account if the checklists are introduced into further schools.

That the majority of whanau members elected to complete the English language version of the checklists likely reflects the situation in many Māori immersion settings where parents' Māori language facility is not as strong as their children's. The parent generation is one of the generations which have suffered extensive language and cultural loss as a result of past colonising practices within mainstream education in New Zealand. However, the parent generation is also the generation which most desires that its children should have educational opportunities that were denied to them.

The checklists thus generated a great deal of useful information, both for developing the Hei Awhina Matua video and training materials and for improving the day-to-day behaviour management strategies within the schools.

Travelling to and from school by bus was among the 10 top-ranked contexts for problem behaviour by students from School 1 and School 2, (Table 7 ). In the case of School 3, travelling to and from school, whether by bus or on foot, is a problematic context since neither school staff nor parents can exercise direct control over students' behaviour.

Travelling on an overcrowded bus made it very difficult for students to behave well. Competition for seating, close physical contact, and students coming from several different schools resulted in a context in which a high rate of shouting, verbal and physical aggression, teasing and bullying occurred. Bus travel was a context students disliked intensely. A positive resolution can result when school authorities establish a system of tangible rewards for good behaviour on buses, rather than relying on the previous negative sanctions. Bus behaviour became one of the skits included in the Hei Awhina Matua video.

School staff and students ranked whole class learning contexts among their top 10 problem behaviour contexts. Whole class learning contexts occur when, for example, a teacher is explaining the task requirements and procedures to a whole class prior to students going off to work in groups. It is likely that these rankings reflected uncertainties about task and procedural requirements in newly-emerging curriculum areas, such as technology. When curriculum documents are not fully understood, advanced planning and 
careful preparation of lesson materials is vital. These, together with clearlyestablished ground rules, avoid frustration and confusion on the part of both students and teachers. A behaviour skit was constructed which emphasises the importance of careful preparation of lesson materials and of praising students who are following classroom rules.

Staff in all three schools also ranked highly school sports, fitness, playtime and other outside activities as contexts in which problem behaviours occurred. These data suggested supervision of playground and sporting activities were concerns that school staff needed to address. The data also identified a need for skills in negotiating and following rules for playground games on the part of school staff and students. Two behaviour skits were developed around these concerns, and ways to resolve them.

Problem behaviour context items selected by school staff or whanau members alone may be items that the adults feel are more their particular responsibility. For example, waking children up and making sure that there is breakfast for them was a concern for whanau members. However, other items may have been seen as a concern because they represent additional workload. For example, lunchtime and playtime settings could represent additional duties for school staff. However, school trips, outings and assemblies could also be of concern because these contexts involve their students being on display to other staff and to people in the community. For whanau members, family outings too, could be a concern because their children are on display, so that their behaviour becomes more of a critical issue.

It was interesting that homework was identified as a high priority context for problem behaviour by all three responder groups. Teachers may have been concerned that homework was not being completed. Students may have felt that they have insufficient support and encouragement to complete their homework tasks. However, another possibility could be that whanau members need specific strategies to assist them to support their students with homework tasks. In an earlier study to support parents to tutor their children who were low achievers in reading, it was found that parents were not lacking in concern or motivation to help their children, but did lack specific strategies for doing so (McNaughton, Glynn \& Robinson, 1981). Part of parents' concern in the present study may have to do with homework which requires facility in Māori. As noted earlier, many of the parents come from a generation which was deprived of language, and so while they are highly motivated to help their children succeed at school, they do not believe they have the language skills to do so.

From the problem behaviour rankings (Table 8) it is clear that both whanau members and students agreed that arguing and fighting with brothers and sisters were the top ranked items. Other problem behaviour items shared between student and whanau member lists, shouting and yelling, not listening, teasing, taunting, not following instructions and stirring were clearly related to arguing and fighting with siblings. These findings provided a strong focus for the home setting skits on the Hei Awhina Matua video.

School staff identified bullying as among their top 10 problem behaviour items, together with other items such as shouting and yelling, not listening, not following instructions, teasing, taunting, interference and stirring. 
Bullying was not included by students or whanau members among their top 10 problem behaviour items. Yet it is clear from Table 8 that all three groups identified the same cluster of problem behaviours among their priority rankings. This could mean that the school staff interpretation of what constitutes bullying does not match that of students or whanau members. However, school staff and whanau members, while identifying specific problem behaviours of concern to them, may not always recognise that these behaviours form part of an extended chain of events. For example, verbal abuse and attention-seeking, identified by school staff and whanau members as priority problem behaviours, may have resulted from prior teasing, taunting or other provocation. This demonstrated a need for the Hei Awhina Matua video and training manual to include behaviour management strategies which address behaviour change through changing antecedents as well as through changing consequences, (Glynn, 1982; Wheldall \& Glynn, 1989). Hence, a skit was developed which depicts a teacher dealing with a student who is pushing and shoving her way into the queue at the school canteen. It turns out that the behaviour displayed related to antecedent events. She had had no breakfast that morning and had only a few minutes in which to buy her lunch or risk being late for an appointment with the school counsellor.

The problem behaviour checklist data suggest also that on the playground students engage with their peers in the same kinds of behaviour that they engage in at home. If these behaviours have been modelled and reinforced or ignored at home, and have not improved by the time students arrive at school or preschool, then they are difficult to change. Further, when a number of students displaying high levels of these behaviours are brought together, escalation and conflict are almost inevitable. Finding effective ways of dealing with these behaviours calls for careful and extended communication between home and school. What must be avoided is the situation where school staff blame parents and students, and where parents blame school staff and students.

The problem behaviours of not listening and not following instructions were ranked highly by all three groups. Yet Table 9 shows that school staff and students were the only groups to rank listening among their most valued behaviours. Listening carefully when others are expressing their concern about our behaviour is a basic communication skill which was needed by students, whanau members and school staff alike. Listening needs to be shared by students, whanau members and school staff as a most valued behaviour at home and at school, if further problem behaviours such as not following instructions, attention-seeking, shouting and yelling are to be reduced. Effective listening was therefore modelled in almost all of the skits included in the video and training manual.

Not listening is likely to contribute also to behaviour problems which arise when students are in peer group contexts, without adult supervision, such as in sports practices or shopping malls after school hours. Data from Figure 1 indicated that students themselves identified going out with friends as a context which was a problem for them. They also ranked the careful choosing of friends second (Table 9) while whanau members ranked it seventh. In School 1, students' ranking of careful choosing of friends as a 
problem behaviour context was surprising. They were quite frank with the researchers in explaining that they found the pressure from peers to join them in undesirable behaviours (e.g. stealing) was often too powerful to resist. They themselves came up with some important antecedent behaviour management strategies for coping with these stressful contexts, such as choosing your friends more carefully, and enlisting the support of a friend to help you to say "no". It seemed that parents and teachers, who did not identify going out with friends as a problem context, had little or no awareness of the pressures students experienced in these situations. This strengthens the call for better communication and greater exchange of information among all three groups.

The three schools in this study were striving to establish a closer working partnership with their students and families. While such a home and school partnership can result in mutual benefits (Wolfendale \& Topping, 1995), the process is not without challenges and difficulties. A close working partnership requires open and effective channels between school staff and whanau members. In these three schools the Hei Awhina Matua checklists provided a useful first step towards a more collaborative home and school approach to behaviour management. For example, positive class and school-wide behaviour plans were developed and implemented by the staff and students in Schools 2 and 3, and have been warmly endorsed by families from these schools.

Experience in this study has shown that an essential component of an effective home and school partnership for managing student behaviour is student participation (Glynn et al., 1996). It is crucial that students themselves are consulted early in the process and are given the opportunity to contribute. The conception and production of the 11 school, home and community skits in the Hei Awhina Matua video and training manual could not have been achieved without the sustained input from the students themselves.

\section{REFERENCES}

Bishop, R. (1994). Initiating empowering research, New Zealand Journal of Educational Studies, 29(1), 1-14

Bishop, R. (1996a). Addressing issues of self-determination and legitimation in kaupapa Māori research. In: He Paepae Korero: Research perspective's in Māori education. Wellington: New Zealand Council for Educational Research.

Bishop, R. (1996b). Collaborative research stories: Whakawhanaungatunga. Palmerston North, Dunmore Press.

Glynn, T., Berryman, M. \& Atvars, K. (1996). Hei Awhina Matua. Video produced by Audiovisual Production Section, Higher Education Development Centre, University of Otago.

Glynn, T., Fairweather, R., \& Donald, S. (1992). Involving parents in improving children's learning at school: Policy issues for behavioural research. Behaviour Change: Special issue on behuvioural family intervention, 9(3),178-185.

Glynn, T. (1982). Antecedent control of behaviour in educational contexts. Educational Psychology, 2(3), 215-229. 
Glynn, T. (1995). Pause prompt praise: Reading tutoring procedures for home and school partnership. In S. Wolfendale \& K. Topping (Eds.) Parental involvement in literacy-effective partnerships in education (ch. 4). London: Cassell.

Glynn, T., Berryman, M., Bidois, P., Atvars, K., Duffull, T., \& Horne, J. (1996). Involving children in research: The Hei Awhina Matua Project. Dunedin: The Children's Issue Centre.

Glynn, T., Berryman, M., Bidois, P., Furlong, M., Walker, R., \& Atvars, K. (1996). Bilingual reading gains for tutors and tutees in a Māori language immersion programme. In: He Paepae Korero: Research perspectives in Mãori education, Wellington, New Zealand Council for Educational Research.

Glynn, T. \& Bishop, R. (1995). Cultural issues in educational research: A New Zealand perspective. He Pukenga Korero, 1(1), 37-43.

Glynn, T., Harawira, W., Stockman, T., Gear P., Walker, W., Reweti, M., Atvars, K., \& Bidois, P. (1996). The Poutama Pounamu Research Whanau: Relationships and Outcomes. Keynote Address, N.Z.A.R.E. Conference, Nelson, December.

Jacka, S., Sutherland, B., Peters, M. \& Smith, L (1996) Te Kupenga: Children adrift in the truancy crisis. Research Report to the Ministry of Education, Wellington.

McNaughton, S., Glynn, T., \& Robinson, V. (1981). Parents as remedial reading tutors: Issues for home and school. Studies in Education No. 28. Wellington: New Zealand Council for Educational Research.

McNaughton, S. S. (1995). Patterns of emergent literacy: Processes of development and transition. Melbourne: Oxford University Press.

Vygotsky, L. S. (1978). Mind in society: The development of higher psychological processes. London: Harvard University Press.

Valsiner, J. (1987). Culture and the development of children's actions: A cultural historical theory of developmental psychology. London: John Wiley.

Younis, J. (1994). Rearing children for society. In J. G. Smentana (Ed.) Beliefs about parenting: origins and developmental implications. New Directions in Child Development, 66, San Francisco: Jossey Bass.

Wheldall, K., \& Glynn, T. (1989). Effective classroom learning. In D. Child (Ed.) Theory and practice of education. Oxford: Basil Blackwell, (in the series Theory and practice of Education). 


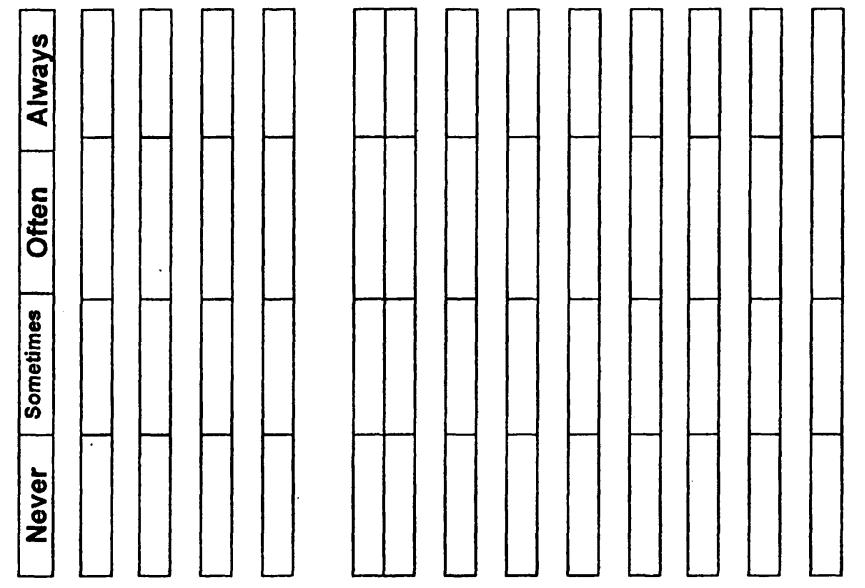

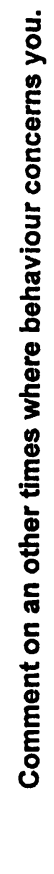
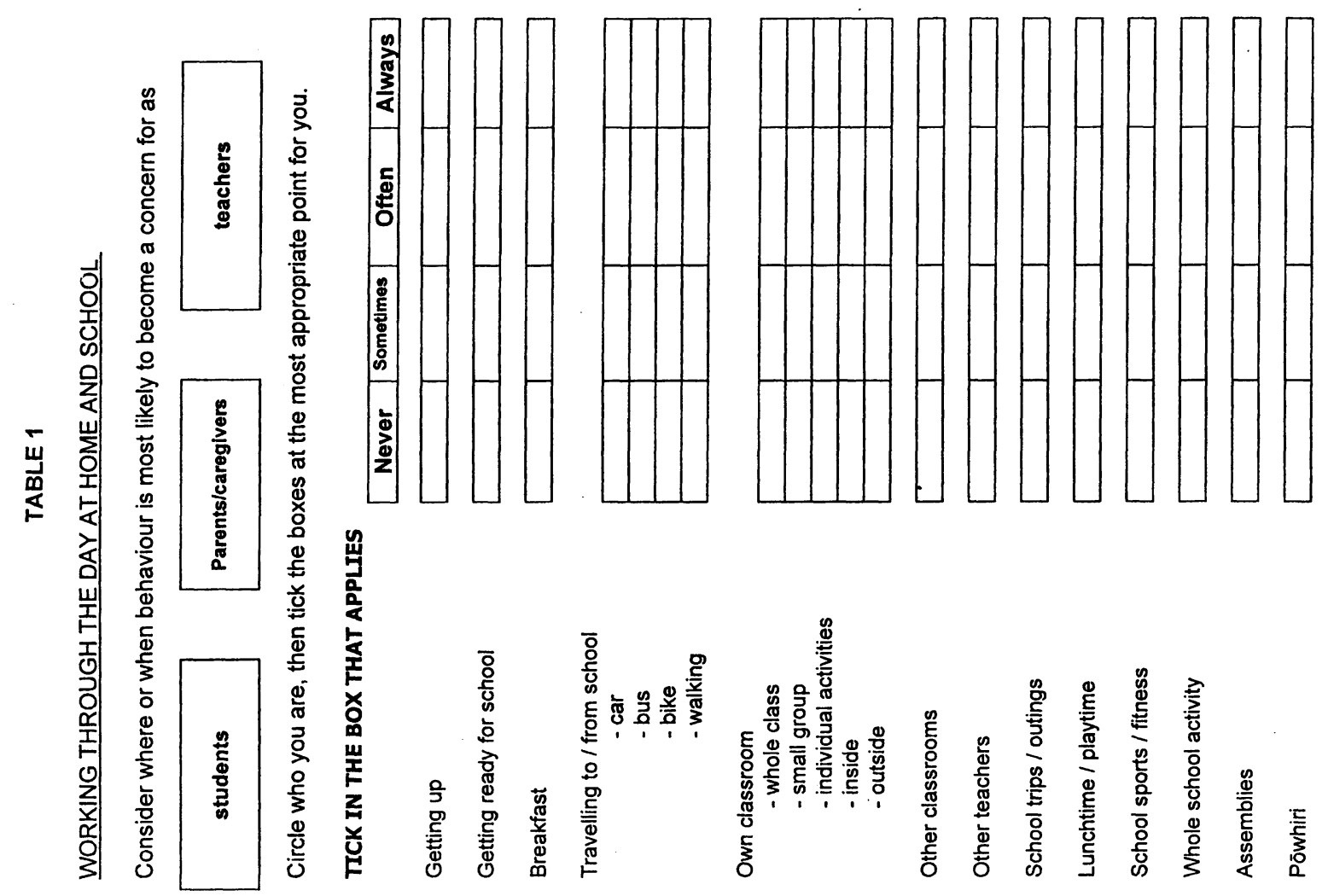
总 

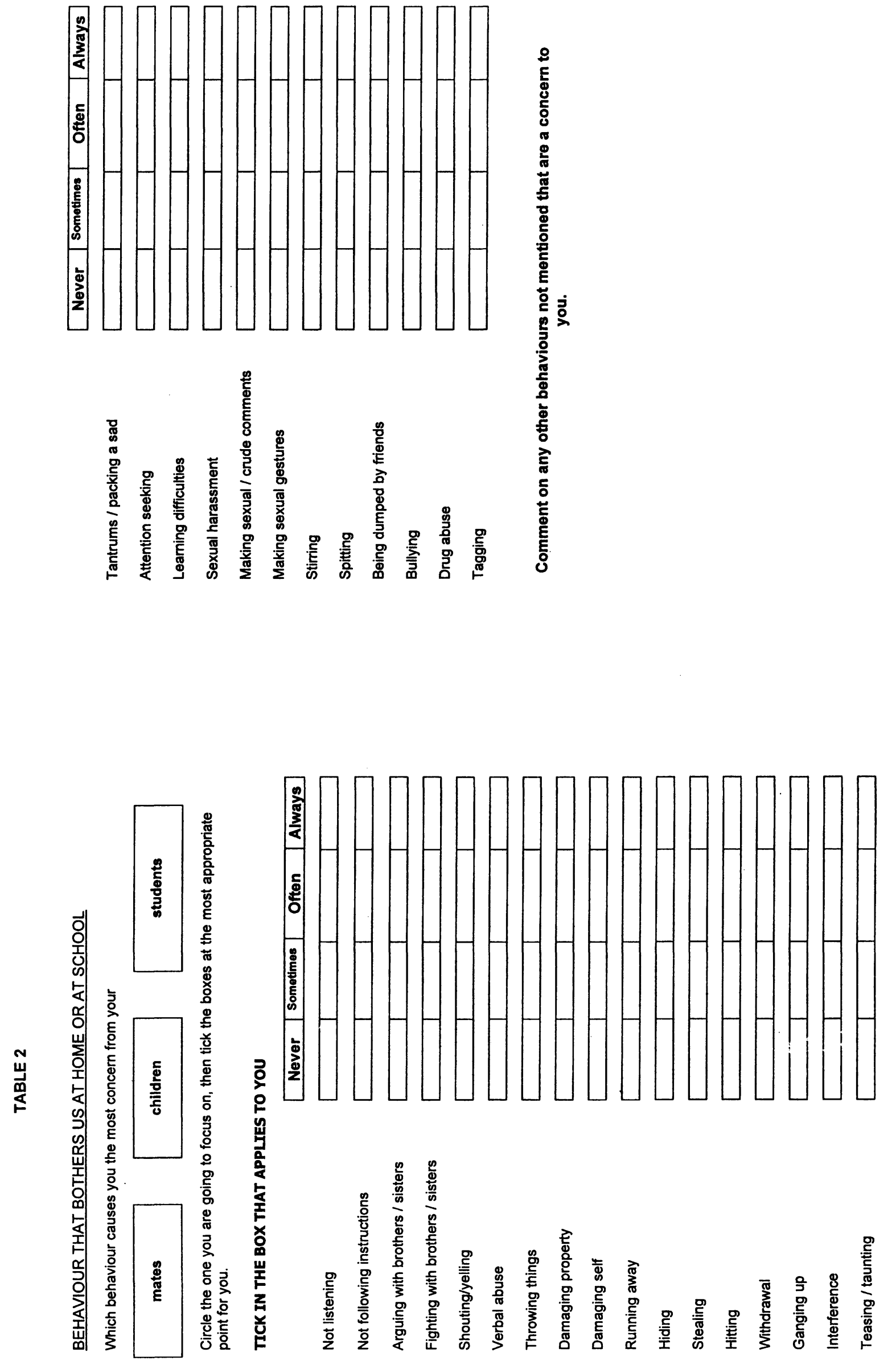

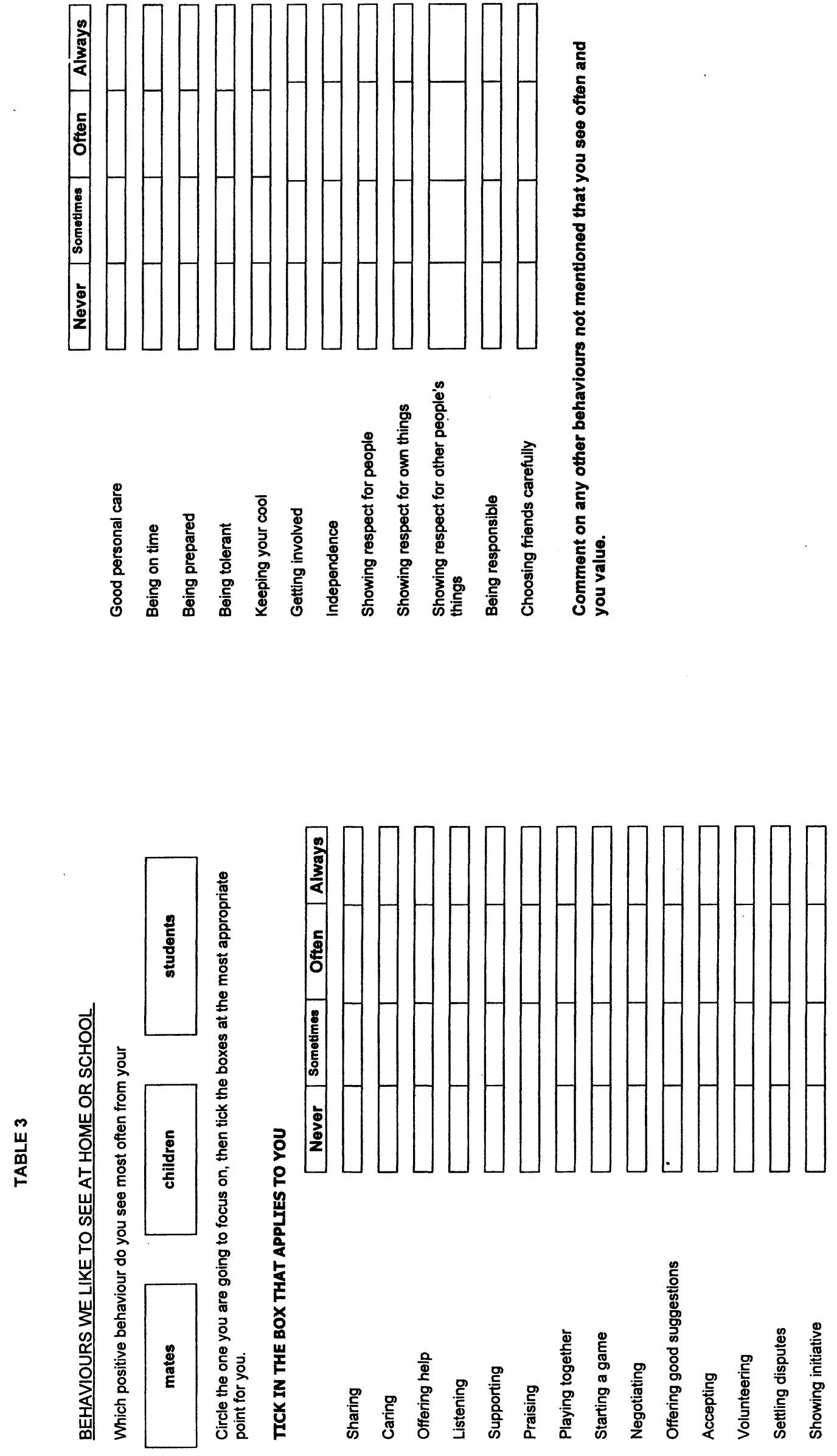

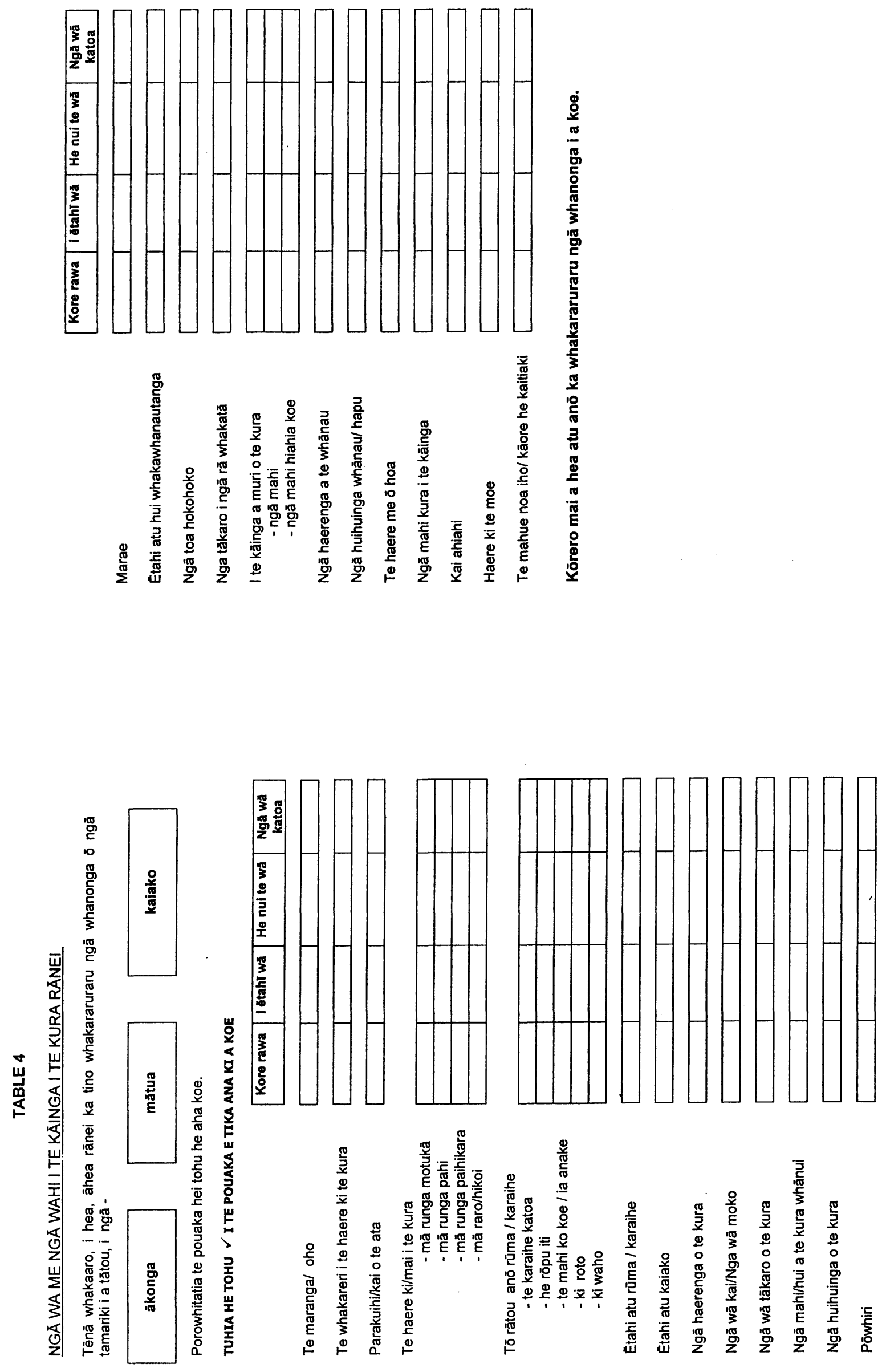

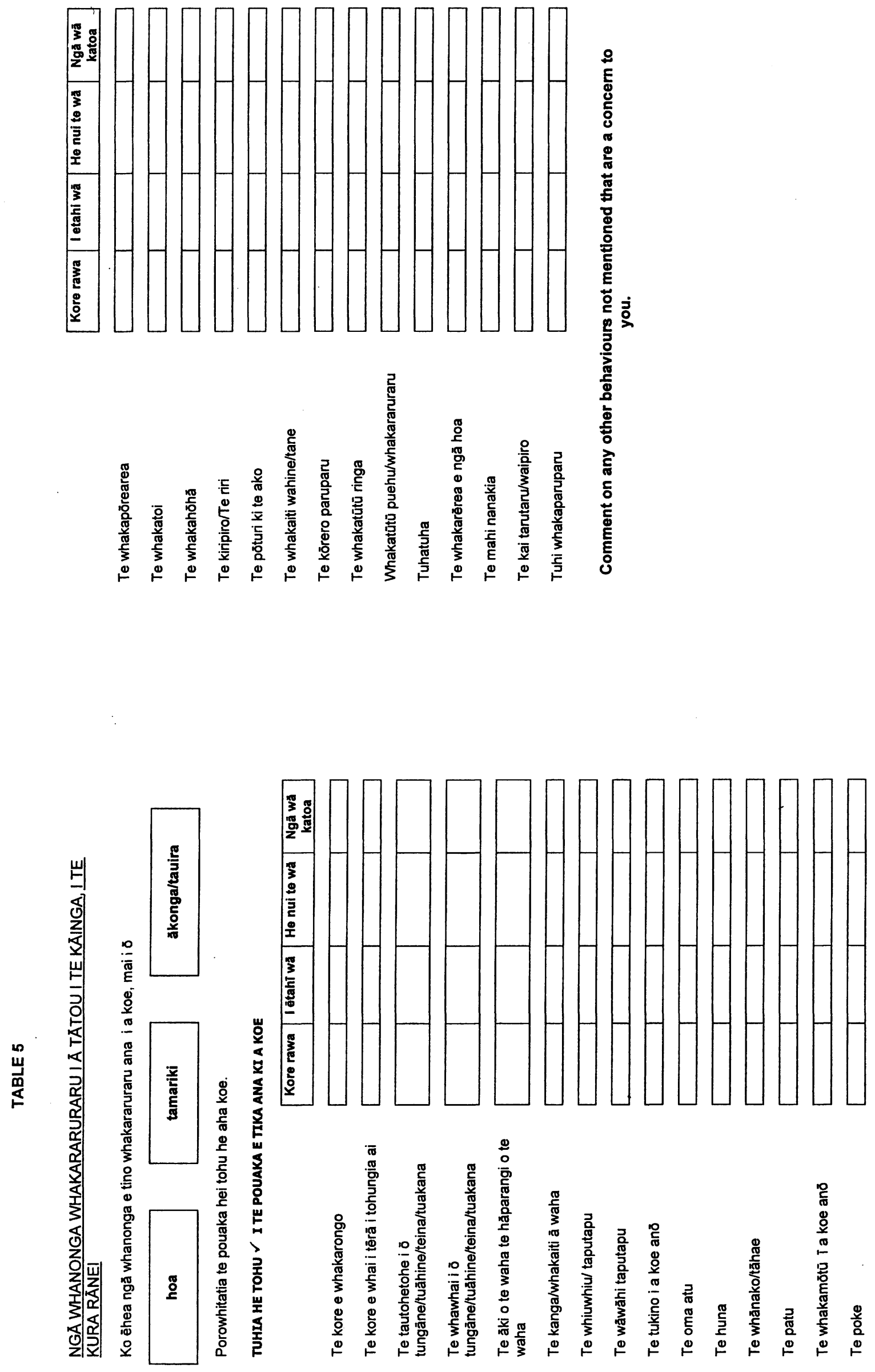

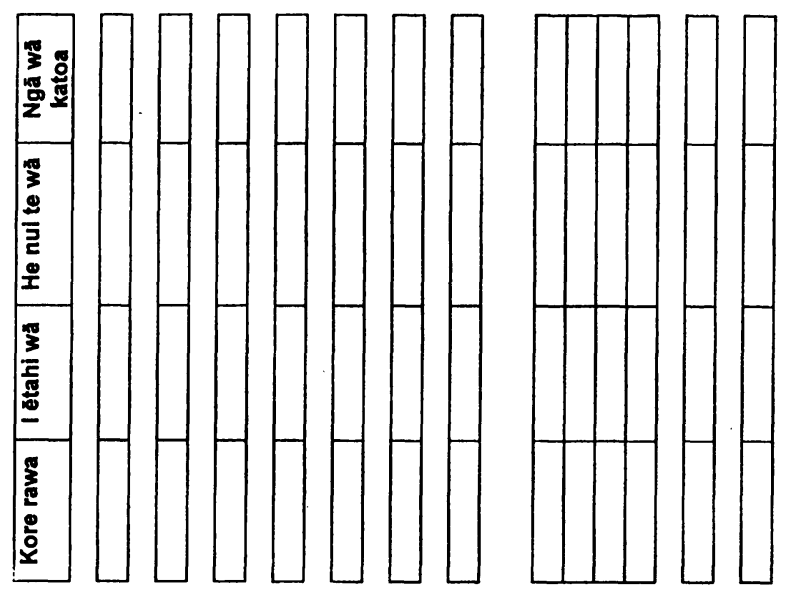

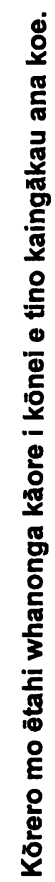

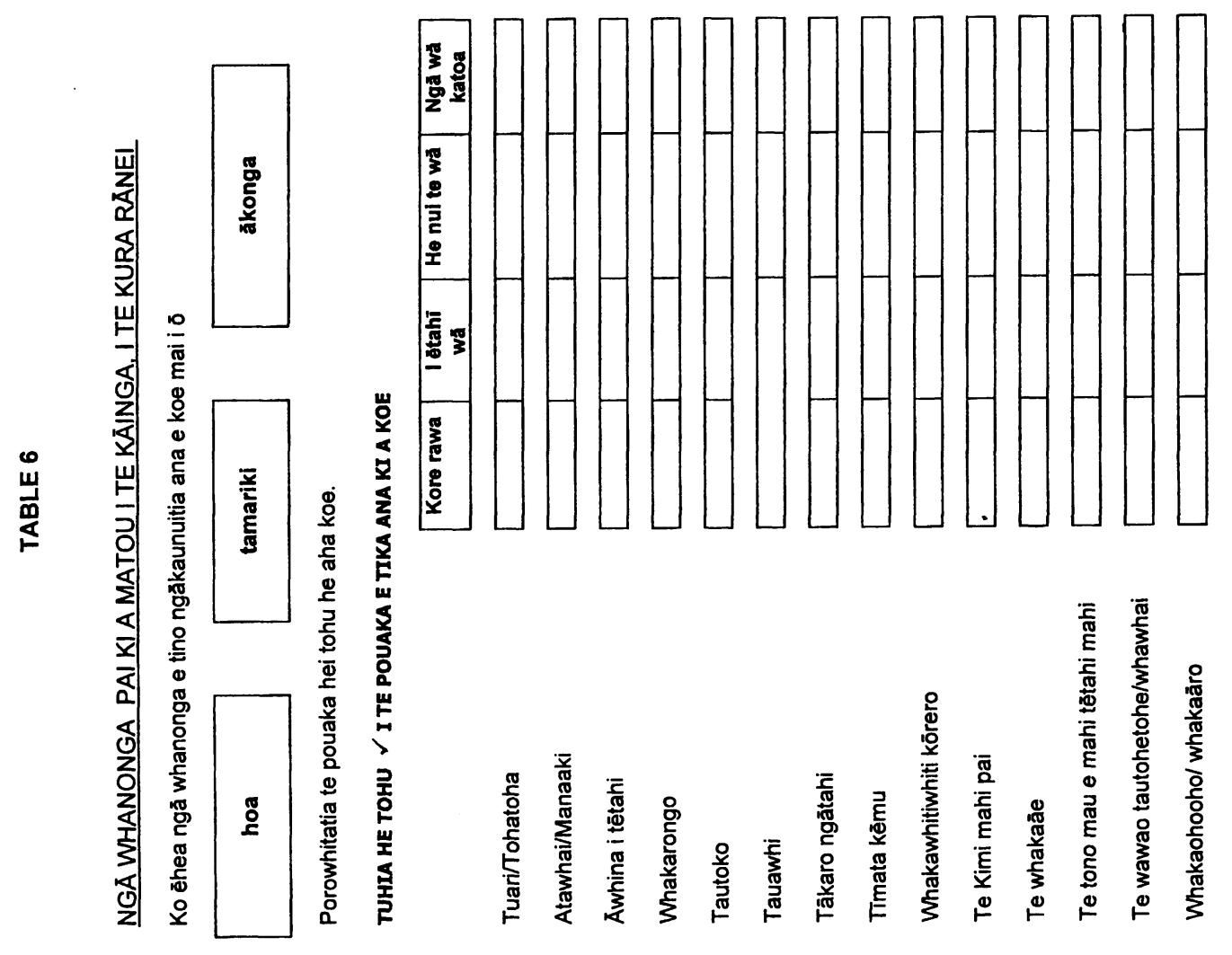


Table 7

PROBLEM CONTEXT RANKINGS

key $\checkmark \checkmark$ top ten rankings

$\checkmark \quad$ 10-15 ranking

\section{Students}

\begin{tabular}{|l|ll|c|c|c|}
\hline & \multicolumn{2}{|c|}{ Ranking } & School 1 & School 2 & School 3 \\
\hline Own classroom - inside & 1 & 1.24 & $\checkmark$ & $\checkmark \checkmark$ & $\checkmark \checkmark$ \\
\hline Getting ready for school & $2=$ & 1.23 & $\checkmark \checkmark$ & $\checkmark$ & $\checkmark \checkmark$ \\
\hline Own classroom - whole class & $2=$ & 1.23 & $\checkmark \checkmark$ & $\checkmark \checkmark$ & $\checkmark$ \\
\hline At home after school, own thing & 4 & 1.22 & $\checkmark \checkmark$ & $\checkmark \checkmark$ & $\checkmark \checkmark$ \\
\hline At home after school, doing jobs & 5 & 1.21 & $\sqrt{ }$ & $\checkmark \checkmark$ & $\checkmark \checkmark$ \\
\hline Homework & 6 & 1.17 & $\checkmark$ & $\checkmark$ & $\checkmark \checkmark$ \\
\hline Going to bed & 7 & 1.11 & $\checkmark$ & $\checkmark \checkmark$ & $\checkmark$ \\
\hline Bus, travel to and from school & 8 & 1.09 & $\checkmark \checkmark$ & $\checkmark \checkmark$ & \\
\hline Out with friends & 9 & 1.08 & $\checkmark \checkmark$ & $\checkmark \checkmark$ & \\
\hline Walk, travel to and from school & $10=$ & 1.07 & $\checkmark \checkmark$ & & $\checkmark \checkmark$ \\
\hline Own room - individual activities & $10=$ & 1.07 & $\checkmark$ & $\checkmark \checkmark$ & $\checkmark \checkmark$ \\
\hline
\end{tabular}

\section{Whānau Members}

\begin{tabular}{|l|ll|c|c|c|}
\hline & \multicolumn{2}{|c|}{ Ranking } & School 1 & School 2 & School 3 \\
\hline At home after school, doing jobs & 1 & 1.63 & $\checkmark \checkmark$ & $\checkmark \checkmark$ & $\checkmark \checkmark$ \\
\hline Getting ready for school & 2 & 1.30 & $\checkmark \checkmark$ & $\checkmark \checkmark$ & $\checkmark \checkmark$ \\
\hline Getting up & 3 & 1.28 & $\checkmark \checkmark$ & $\checkmark \checkmark$ & $\checkmark \checkmark$ \\
\hline At home after school, own thing & 4 & 1.20 & $\checkmark \checkmark$ & $\checkmark \checkmark$ & $\checkmark \checkmark$ \\
\hline Going to bed & 5 & 1.19 & $\checkmark \checkmark$ & $\checkmark \checkmark$ & $\checkmark \checkmark$ \\
\hline Homework & 6 & 1.17 & $\checkmark \checkmark$ & $\checkmark \checkmark$ & $\checkmark \checkmark$ \\
\hline Breakfast & 7 & 1.15 & $\checkmark \checkmark$ & $\checkmark \checkmark$ & $\checkmark \checkmark$ \\
\hline Evening Meal & 8 & 1.03 & $\checkmark \checkmark$ & $\checkmark \checkmark$ & $\checkmark \checkmark$ \\
\hline Shopping Centre & 9 & 1.00 & $\checkmark$ & $\checkmark \checkmark$ & $\checkmark \checkmark$ \\
\hline Family outings & 10 & 0.97 & $\checkmark \checkmark$ & $\checkmark \checkmark$ & $\checkmark$ \\
\hline
\end{tabular}

\section{School Staff}

\begin{tabular}{|l|ll|c|c|c|}
\hline & \multicolumn{2}{|c|}{ Ranking } & School 1 & School 2 & School 3 \\
\hline School sports and fitness & 1 & 1.58 & $\checkmark \checkmark$ & $\checkmark \checkmark$ & $\checkmark \checkmark$ \\
\hline Other classrooms & 2 & 1.44 & $\checkmark \checkmark$ & $\checkmark \checkmark$ & $\checkmark \checkmark$ \\
\hline Lunchtime / playtime & $3=$ & 1.35 & $\checkmark$ & $\checkmark \checkmark$ & $\checkmark \checkmark$ \\
\hline Own classroom - outside & $3=$ & 1.35 & $\checkmark \checkmark$ & $\checkmark \checkmark$ & $\checkmark \checkmark$ \\
\hline School trips and outings & 5 & 1.33 & $\checkmark \checkmark$ & $\checkmark \checkmark$ & $\checkmark \checkmark$ \\
\hline Assemblies & 6 & 1.26 & $\checkmark \checkmark$ & $\checkmark \checkmark$ & $\checkmark \checkmark$ \\
\hline Own classroom - whole class & 7 & 1.25 & $\checkmark \checkmark$ & $\checkmark \checkmark$ & $\checkmark$ \\
\hline Whole school activity & 8 & 1.22 & $\checkmark \checkmark$ & $\checkmark$ & $\checkmark \checkmark$ \\
\hline Own classroom - inside & 9 & 1.20 & $\checkmark \checkmark$ & $\checkmark \checkmark$ & $\checkmark$ \\
\hline Marae & $10=$ & 1.19 & $\checkmark$ & $\checkmark \checkmark$ & $\checkmark \checkmark$ \\
\hline Homework & $10=$ & 1.19 & $\checkmark \checkmark$ & $\checkmark$ & $\checkmark$ \\
\hline
\end{tabular}


Table 8

\section{PROBLEM BEHAVIOUR RANKINGS}

key $\checkmark \checkmark$ top ten rankings
$\checkmark$ 10-15 ranking

\section{Students}

\begin{tabular}{|c|c|c|c|c|c|}
\hline & \multicolumn{2}{|c|}{ Ranking } & School 1 & School 2 & School 3 \\
\hline Arguing with brothers \& sisters & 1 & 1.71 & $\sqrt{ }$ & & \\
\hline Fighting with brothers \& sisters & 2 & 1.44 & $\sqrt{ }$ & 7 & \\
\hline Shouting and yelling & 3 & 1.39 & $\checkmark$ & $\sqrt{ }$ & \\
\hline Not listening & 4 & 1.34 & & $\sqrt{ }$ & \\
\hline Teasing / taunting & 5 & 1.29 & $\sqrt{ }$ & $\sqrt{ }$ & \\
\hline Spitting & 6 & 1.24 & $\checkmark$ & $\checkmark$ & \\
\hline Hitting & $7=$ & 1.2 & $\sqrt{ }$ & $\sqrt{ }$ & $\sqrt{ }$ \\
\hline Not following instructions & $7=$ & 1.2 & $\sqrt{ }$ & $\sqrt{ }$ & $\sqrt{ }$ \\
\hline Interference & $9=$ & 1.12 & & $\sqrt{ }$ & $\sqrt{ }$ \\
\hline Stirring & $9=$ & $\overline{1.12}$ & $\sqrt{ }$ & & $\sqrt{ }$ \\
\hline
\end{tabular}

\section{Whānau Members}

\begin{tabular}{|l|ll|c|c|c|}
\hline & \multicolumn{2}{|c|}{ Ranking } & School 1 & School 2 & School 3 \\
\hline Arguing with brothers \& sisters & 1 & 1.84 & $\sqrt{ }$ & $\checkmark \checkmark$ & $\checkmark \checkmark$ \\
\hline Fighting with brothers \& sisters & 2 & 1.64 & $\checkmark \checkmark$ & $\checkmark \checkmark$ & $\checkmark \checkmark$ \\
\hline Not listening & 3 & 1.47 & $\checkmark \checkmark$ & $\checkmark \checkmark$ & $\checkmark \checkmark$ \\
\hline Shouting and yelling & 4 & 1.46 & $\sqrt{ }$ & $\checkmark \checkmark$ & $\checkmark \checkmark$ \\
\hline Teasing / taunting & 5 & 1.29 & $\checkmark \checkmark$ & $\checkmark \checkmark$ & $\checkmark \checkmark$ \\
\hline Not following instructions & 6 & 1.26 & $\checkmark \checkmark$ & $\checkmark \checkmark$ & $\checkmark \checkmark$ \\
\hline Tantrums / packing a sad & 7 & 1.14 & $\checkmark \checkmark$ & $\checkmark \checkmark$ & $\checkmark \checkmark$ \\
\hline Attention seeking & 8 & 1.11 & $\checkmark \checkmark$ & $\checkmark \checkmark$ & $\checkmark \checkmark$ \\
\hline Verbal abuse & 9 & 0.99 & $\checkmark \checkmark$ & $\checkmark \checkmark$ & $\checkmark$ \\
\hline Stirring & 10 & 0.97 & $\checkmark \checkmark$ & $\checkmark \checkmark$ & $\checkmark \checkmark$ \\
\hline
\end{tabular}

\section{School Staff}

\begin{tabular}{|l|cc|c|c|c|}
\hline & \multicolumn{2}{|c|}{ Ranking } & School 1 & School 2 & School 3 \\
\hline Not listening & 1 & 1.64 & $\sqrt{ }$ & $\sqrt{ }$ & $\checkmark \checkmark$ \\
\hline Not following instructions & 2 & 1.60 & $\sqrt{ }$ & $\checkmark \checkmark$ & $\checkmark \checkmark$ \\
\hline Shouting / yelling & 3 & 1.31 & $\checkmark \checkmark$ & $\checkmark \checkmark$ & $\checkmark \checkmark$ \\
\hline Learning difficulties & 4 & 1.27 & $\sqrt{ }$ & $\checkmark$ & $\checkmark \checkmark$ \\
\hline Teasing / taunting & 5 & 1.26 & $\checkmark \checkmark$ & $\checkmark \checkmark$ & $\checkmark \checkmark$ \\
\hline Interference & $6=$ & 1.18 & $\sqrt{ }$ & $\checkmark \checkmark$ & $\checkmark \checkmark$ \\
\hline Attention seeking & $6=$ & 1.18 & $\checkmark$ & $\checkmark \checkmark$ & $\checkmark \checkmark$ \\
\hline Verbal abuse & $8=$ & 1.15 & $\checkmark \checkmark$ & $\checkmark$ & $\checkmark \checkmark$ \\
\hline Stirring & $8=$ & 1.15 & $\checkmark \checkmark$ & $\checkmark \checkmark$ & $\checkmark \checkmark$ \\
\hline Bullying & 10 & 1.08 & $\checkmark \checkmark$ & $\checkmark \checkmark$ & \\
\hline
\end{tabular}


Table 9

MOST VALUED BEHAVIOURS RANKINGS

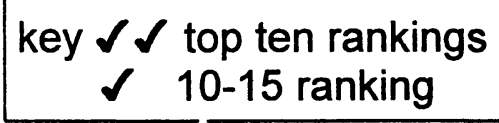

\section{Students}

\begin{tabular}{|l|ll|c|c|c}
\hline & Ranking & School 1 & School 2 & School 3 \\
\hline Playing together & 1 & 1.91 & $\checkmark \checkmark$ & $\checkmark \checkmark$ & $\checkmark \checkmark$ \\
\hline Choosing friends carefully & 2 & 1.69 & $\checkmark \checkmark$ & $\checkmark \checkmark$ & $\checkmark \checkmark$ \\
\hline Sharing & 3 & 1.68 & $\checkmark \checkmark$ & $\checkmark \checkmark$ & $\checkmark$ \\
\hline Caring & 4 & 1.64 & $\checkmark \checkmark$ & $\checkmark \checkmark$ & $\checkmark \checkmark$ \\
\hline Listening & $5=$ & 1.61 & $\checkmark$ & $\checkmark \checkmark$ & $\checkmark$ \\
\hline Being prepared & $5=$ & 1.61 & $\checkmark$ & $\checkmark \checkmark$ & $\checkmark \checkmark$ \\
\hline Supporting & $7=$ & 1.59 & $\checkmark \checkmark$ & $\checkmark \checkmark$ & $\checkmark$ \\
\hline Good personal care & $7=$ & 1.59 & $\checkmark \checkmark$ & $\checkmark$ & $\checkmark \checkmark$ \\
\hline Being on time & 9 & 1.55 & $\checkmark \checkmark$ & & $\checkmark \checkmark$ \\
\hline Being responsible & 10 & 1.54 & $\checkmark \checkmark$ & & $\checkmark \checkmark$ \\
\hline
\end{tabular}

\section{Whānau Members}

\begin{tabular}{|l|ll|c|c|c}
\hline & \multicolumn{2}{|c|}{ Ranking } & School 1 & School 2 & School 3 \\
\hline Sharing & $1=$ & 2.12 & $\checkmark$ & $\checkmark \checkmark$ & $\sqrt{ }$ \\
\hline Caring & $1=$ & 2.12 & $\checkmark \checkmark$ & $\checkmark \checkmark$ & $\checkmark \checkmark$ \\
\hline Showing respect for people & 3 & 2.09 & $\checkmark \checkmark$ & $\checkmark \checkmark$ & $\checkmark \checkmark$ \\
\hline Good personal care & 4 & 2.08 & $\checkmark \checkmark$ & $\checkmark \checkmark$ & $\checkmark \checkmark$ \\
\hline Being responsible & 5 & 2.04 & $\checkmark \checkmark$ & $\checkmark \checkmark$ & $\checkmark \checkmark$ \\
\hline Offering help & 6 & 2.00 & $\checkmark \checkmark$ & $\checkmark \checkmark$ & $\checkmark \checkmark$ \\
\hline Choosing friends carefully & 7 & 1.96 & $\checkmark \checkmark$ & $\checkmark$ & $\checkmark \checkmark$ \\
\hline Respect for people's things & 8 & 1.93 & $\checkmark \checkmark$ & $\checkmark \checkmark$ & $\checkmark$ \\
\hline Independence & 9 & 1.92 & $\checkmark$ & $\checkmark \checkmark$ & $\checkmark \checkmark$ \\
\hline Respect for own things & 10 & 1.90 & $\checkmark \checkmark$ & $\checkmark \checkmark$ & \\
\hline
\end{tabular}

\section{School Staff}

\begin{tabular}{|l|ll|c|c|c}
\hline & \multicolumn{2}{|c|}{ Ranking } & School 1 & School 2 & School 3 \\
\hline Caring & 1 & 2.13 & $\checkmark \checkmark$ & $\checkmark \checkmark$ & $\checkmark \checkmark$ \\
\hline Listening & 2 & 1.98 & $\checkmark \checkmark$ & $\checkmark \checkmark$ & $\checkmark$ \\
\hline Good personal care & $3=$ & 1.93 & $\checkmark$ & $\checkmark$ & $\checkmark \checkmark$ \\
\hline Showing respect for people & 4 & 1.90 & $\checkmark \checkmark$ & $\checkmark \checkmark$ & $\checkmark$ \\
\hline Sharing & 5 & 1.86 & $\checkmark \checkmark$ & $\checkmark \checkmark$ & $\checkmark \checkmark$ \\
\hline Playing together & $6=$ & 1.83 & & $\checkmark$ & $\checkmark \checkmark$ \\
\hline Being responsible & $6=$ & 1.83 & $\checkmark \checkmark$ & & $\checkmark \checkmark$ \\
\hline Getting involved & 8 & 1.82 & $\checkmark$ & $\checkmark$ & $\checkmark \checkmark$ \\
\hline Offering help & $9=$ & 1.80 & $\checkmark \checkmark$ & $\checkmark \checkmark$ & $\checkmark$ \\
\hline Supporting & $9=$ & 1.80 & $\checkmark \checkmark$ & $\checkmark \checkmark$ & \\
\hline
\end{tabular}

